\title{
Evidências de Indução de Resistência Sistêmica à Ferrugem do Eucalipto Mediada por Rizobactérias Promotoras do Crescimento de Plantas*
}

\author{
Débora A. Teixeira, Acelino C. Alfenas, Reginaldo G. Mafia, Luiz A. Maffia \& Eraclides M. Ferreira \\ Departamento de Fitopatologia, Universidade Federal de Viçosa, CEP 36570-000, Viçosa, MG, e-mail: aalfenas@ufv.br
}

(Aceito para publicação em 08/09/2004)

Autor para correspondência: Acelino C. Alfenas

TEIXEIRA, D.A., ALFENAS, A.C., MAFIA, R.G., MAFFIA, L.A. \& FERREIRA, E.M. Evidências de indução de resistência sistêmica à ferrugem do eucalipto mediada por rizobactérias promotoras do crescimento de plantas. Fitopatologia Brasileira 30:350-356 2005 .

\section{RESUMO}

A indução de resistência sistêmica mediada por rizobactérias promotoras do crescimento de plantas foi avaliada para a ferrugem do eucalipto (Eucalyptus spp.) causada por Puccinia psidii. Para isso, mudas com cerca de 80 dias de idade, previamente enraizadas em substrato tratado com diferentes isolados de rizobactérias foram inoculadas com uma suspensão de inóculo de P. psidii ajustada para $2 \times 10^{4}$ urediniósporos $/ \mathrm{ml}$. As plantas inoculadas foram mantidas em câmara de nevoeiro com nebulização intermitente a $25^{\circ} \mathrm{C}$, no escuro por $24 \mathrm{~h}$, e posteriormente transferidas para câmara de crescimento a $22^{\circ} \mathrm{C}$, com fotoperíodo de $12 \mathrm{~h}$ e intensidade luminosa de $40 \mu$ moles. $\mathrm{s}^{-1} \cdot \mathrm{m}^{-2}$. Utilizou-se um delineamento inteiramente casualizado com quatro repetições, cada uma delas com quatro plantas. Após 13 dias da inoculação, avaliaram-se número médio de pústulas/folha, número de uredínias/amostra e número médio de esporos produzidos/uredínia. Os isolados FL2 e MF4 foram eficientes na redução da severidade da ferrugem. Além disso, o tratamento das mudas com rizobactérias, apenas uma semana antes da inoculação, com $P$. psidii foi menos eficiente em reduzir a severidade da doença do que o tratamento em que foram utilizadas mudas produzidas em substrato previamente rizobacterizadas, ou seja, com 80 dias. Estes resultados indicam que estes isolados de rizobactérias podem induzir maior resistência a doenças foliares diminuindo a necessidade de aplicação de fungicidas e otimizando a produção de mudas clonais de eucalipto.

Palavras-chave adicionais: clonagem, miniestaquia, estaquia, PGPR's, indução de resistência sistêmica.

\begin{abstract}
Evidence of induction of systemic resistance to eucalyptus rust by plant growth promoting rhizobacteria

Induction of systemic resistance (ISR) by plant growth promoting rhizobacteria was tested against eucalypt (Eucalyptus spp.) rust caused by Puccinia psidii. Nearly 80 day old cuttings, previously rooted in rhizobacteria-treated and untreated (control) substrate, were inoculated with a $2 \times 10^{4} \mathrm{P}$. psidii urediniospore $/ \mathrm{ml}$ suspension. The inoculated plants were incubated in an intermittent mist growth chamber at $25{ }^{\circ} \mathrm{C}$, in the dark for $24 \mathrm{~h}$. Subsequently, the plants were maintained at $22{ }^{\circ} \mathrm{C}$ and $12 \mathrm{~h}$ photoperiod at $40 \mu$ moles (photons). $\mathrm{s}^{-1} \cdot \mathrm{m}^{-2}$ light intensity. A completely randomized design with four replications and four plants each was used. After 13 days of inoculation, the mean number of pustules/leaf, number of uredinias/sample and the mean number of spores produced/uredinia were scored. Among the rhizobacterial isolates tested, FL2 and MF4 were significantly more efficient in reducing rust severity. This test was repeated and the same trend was found. These two best rhizobacterium isolates were not as efficient in reducing rust infection when inoculated on the same clone seven days before inoculation as they were when cuttings were rooted in rhizobacterial treated substrate.
\end{abstract}

Additional keywords: cloning, cutting, PGPR's, systemic resistance induction.

\section{INTRODUÇÃO}

Atualmente, o Brasil ocupa a segunda posição no cenário mundial em termos de área plantada com espécies do gênero Eucalyptus, totalizando aproximadamente três milhões de hectares (Campinhos Jr., 1999; FAO, 2000; Mora \& Garcia, 2000). O eucalipto (Eucalyptus spp.), após sua introdução para fins comerciais, originalmente no Estado de São Paulo, manteve-se praticamente livre de doenças até

*Parte da dissertação de doutorado da primeira autora. UFV (2001); Depósitos de patente: (INPI) PI 0101400-5; 001409 e registro da marca Rizolyptus (002852) o início de 1970. Todavia, com a expansão das áreas reflorestadas para regiões mais quentes e úmidas, o plantio de espécies, procedências ou clones suscetíveis e os ciclos sucessivos da cultura têm favorecido a incidência de várias doenças. Dentre essas, a ferrugem causada por Puccinia psidii Winter tem sido limitante ao estabelecimento de novos plantios e à condução por rebrota de materiais suscetíveis, após o corte raso. Além disso, esta doença tem ocorrido em mini-jardins clonais destinados à produção de brotos para miniestaquia e tem afetado a multiplicação clonal do eucalipto. Diante destes aspectos, têm-se buscado alternativas no controle integrado desta e de outras doenças importantes 
do eucalipto, notadamente com o emprego de rizobactérias promotoras do crescimento de plantas (Alfenas \& Mafia, 2003).

Os mecanismos de defesa das plantas podem ser ativados por um estímulo apropriado. Geralmente, essa indução de resistência é sistêmica e seu efeito pode ser observado em locais da planta distantes do local de aplicação do indutor. No entanto, às vezes ocorre somente de forma localizada. Assim, geralmente, considera-se que indução de resistência adquirida (SAR - "Systemic Acquired Resistance") envolve o acúmulo de PRPs (Proteínas Relacionadas com a Patogênese) como mecanismo induzido de defesa da planta. A sua indução é salicilato-dependente e pode resultar em alterações visuais (necroses, por exemplo) na planta que sofreu indução. Enquanto isso, a indução de resistência sistêmica (ISR - "Induced Systemic Resistance") não envolve o acúmulo de PRPs, não promove alterações na planta que sofreu indução, não ocorre nem dependência do salicilato; parecendo haver outra rota de sinalização mais associada a jasminatos e etileno (Van Loon et al., 1997; Pieterse et al., 1998; Van Loon et al., 1998). Entretanto, em alguns casos, a ISR pode ser não só fenotipicamente, mas também, sob o ponto de vista de mecanismo, idêntica a SAR, levando a um acúmulo de proteínas RPs e dependente de salicilato (Van Loon et al., 1997).

Em relação ao agente indutor, na indução de resistência do tipo SAR, ocorre o envolvimento de indutores químicos ou microrganismos não patogênicos, formas avirulentas ou raças incompatíveis de um patógeno, ou patógenos virulentos (Van Loon et al., 1998). Na resistência do tipo ISR, especificamente, ocorre a participação de microrganismos não patogênicos, embora o fenômeno seja similar (Kloepper et al., 1992).

Dentre os microrganismos não patogênicos capazes de induzir resistência sistêmica em plantas, a eficiência de rizobactérias promotoras de crescimento tem sido extensivamente estudado. Rizobactérias não patogênicas podem induzir em plantas resistência sistêmica a vários patógenos, como demonstrado para várias espécies de fungos, bactérias e vírus. Os principais determinantes bacterianos de indução de resistência sistêmica, que podem funcionar como elicitores, são os lipopolissacarídeos presentes na membrana (LPS), sideróforos e o ácido salicílico (Van Loon et al., 1998).

A separação espacial entre patógeno e indutor fornece evidências da ocorrência ou não da resistência sistêmica. Além disso, esse tipo de resposta necessita de um tempo de ativação para ser observada e é efetiva contra uma ampla gama de fitopatógenos (Steiner \& Schönbeck, 1995; Romeiro, 1999). Nesse sentido, o presente trabalho objetivou avaliar a possível indução de resistência sistêmica, mediada por isolados pré-selecionados de rizobactérias promotoras do crescimento de eucalipto, sobre a ferrugem e o efeito do tempo de ativação da resposta de resistência.

\section{MATERIAL E MÉTODOS}

Empregaram-se dez isolados de rizobactérias, obtidos a partir da rizosfera e rizoplano de mudas clonais de eucalipto de diferentes regiões do país. Estes microrganismos foram pré-selecionados de acordo com a capacidade em promover incremento na biomassa de raízes e induzir o enraizamento adventício (Teixeira, 2001). Após identificação por meio da análise filogenética de seqüências parciais de DNA ribossomal 16S (rDNA 16S) (Tabela 1), os isolados foram depositados na coleção do Laboratório de Patologia Florestal (UFV).

Para proceder ao preparo das suspensões rizobacterianas, cada isolado foi cultivado separadamente em meio de Kado \& Heskett (1970) por 48 h, no escuro. Após este período, o crescimento bacteriano foi raspado em solução salina ( $\mathrm{NaCl}$ 0,85\%). As concentrações das suspensões foram ajustadas de acordo com a correlação entre a densidade ótica e número de unidades formadoras de colônias (u.f.c.) para 0,2 Abs. (540 nm), o que corresponde aproximadamente a $10^{8}$ u.f.c. $/ \mathrm{ml}$.

\section{Indução de resistência à ferrugem (Puccinia psidii)}

As mudas utilizadas nos ensaios foram produzidas em um viveiro florestal localizado em Belo Oriente - MG. Para tanto, tubetes plásticos cônicos ( $50 \mathrm{ml}$ de capacidade), contendo substrato à base de casca de arroz carbonizada:vermiculita (1:1) foram tratados com $10 \mathrm{ml}$ da suspensão de cada isolado de rizobactéria. O tratamento testemunha foi realizado apenas com água estéril. Após esta fase, miniestacas com aproximadamente $6-8 \mathrm{~cm}$ de um clone comercial de eucalipto, híbrido de Eucalyptus grandis Hill ex Maiden X E. urophylla S.T. Black foram tratadas com uma solução de AIB (ácido indol butírico a 500 ppm), imediatamente estaqueadas no substrato previamente rizobacterizado e transferidas para casa de enraizamento dotada de nebulização intermitente (UR $\geq 80 \%$ ) e temperatura controlada $\left(25-30{ }^{\circ} \mathrm{C}\right)$. Após 30 dias, as mudas foram transferidas para aclimatação à sombra $(50 \%$ da intensidade

TABELA 1 - Identificação por meio da análise filogenética de seqüências parciais de DNA ribossomal 16S (rDNA 16S) dos isolados de rizobactérias selecionados como promotores de enraizamento em estacas de eucalipto (Eucalyptus spp.)

\begin{tabular}{cl}
\hline \hline $\begin{array}{c}\text { Código do } \\
\text { isolado }\end{array}$ & Identificação \\
\hline R1 & Frauteria aurantia Swings et al., 1980 \\
FL1 & F. aurantia \\
MF4 & Pseudomonas sp. Migula, 1894 \\
MF2 & Pseudomonas sp. \\
Ca & P. fulva Lizuga \& Komagata, 1963 \\
FL2 & P. aeruginosa (Schroeter, 1872) Migula, 1900 \\
CIIb & Stenotrophomonas maltophilia (Hugh 1981) Palleroni \& \\
& Bradbury 1993/ S. nitritireducens Finkmann et al., 2000 \\
S1 & $\begin{array}{l}\text { Bacillus subtilis Cohn, 1872/ B. vallismortis Roberts } \text { et } \\
\text { al., 1996 }\end{array}$ \\
S2 & $\begin{array}{l}\text { B. subtilis /B. vallismortis } \\
3918\end{array}$ \\
Bacillus subtilis /B. vallismortis
\end{tabular}


solar a céu aberto) e finalmente aclimatadas a céu aberto. Decorridos 80 dias do estaqueamento, as mudas obtidas foram utilizadas nas inoculações visando avaliar a possível indução de resistência sistêmica.

Nas inoculações, empregou-se um isolado de $P$. psidii obtido de Eucalyptus sp. em Belo Oriente, MG. Esse isolado foi multiplicado em mudas de jambeiro (Sygyzium jambos (L.) Alston e os urediniósporos coletados aos 12 dias após a inoculação. Os urediniósporos foram transferidos para água com Tween $80(0,05 \%)$ e atomizados $\left(2 \times 10^{4}\right.$ esporos $\left./ \mathrm{ml}\right)$ em ambas as faces dos limbos foliares com auxílio de um atomizador do tipo De Vilbiss $\mathrm{n}^{\circ} 15$, acoplado a um compressor elétrico $\left(0,6-0,8 \mathrm{kgf} / \mathrm{cm}^{2}\right)$. As mudas inoculadas foram mantidas em câmara com irrigação do tipo microaspersão, no escuro por $24 \mathrm{~h}$, e posteriormente levadas para câmara de crescimento a $22{ }^{\circ} \mathrm{C}$, com fotoperíodo de $12 \mathrm{~h}$ (Ruiz et al., 1989) e intensidade luminosa de $40 \mu$ moles (fótons). $\mathrm{s}^{-1} \cdot \mathrm{m}^{-2}$. As avaliações foram feitas 13 dias após a inoculação utilizando-se uma escala diagramática com quatro classes de severidade (S0, S1, S2 e S3) (Junghans, 2000) e quantificando-se o números médio de pústulas por folha, uredínias por área foliar $\left(1,13 \mathrm{~cm}^{2}\right)$ e de esporos por uredínia (Ruiz et al., 1989). Este ensaio foi repetido em duas épocas diferentes a fim de confirmar os resultados obtidos. Utilizaram-se quatro repetições, cada uma com quatro plantas, em delineamento inteiramente casualizado.

Inicialmente, o segundo e terceiro par de folhas de cada planta foram avaliados visualmente. No segundo ensaio, o diâmetro de 40 pústulas de cada repetição e o número de uredínias foram determinados em um microscópio estereoscópico com uma escala métrica acoplada, a fim de assegurar o melhor uso da escala de severidade que se baseia no tipo de reação da planta, diâmetro das pústulas e número de uredínias por pústula.

Para avaliar o número médio de pústulas/folha, uredínias/área foliar e esporos/uredínia empregaram-se o segundo e terceiro par de folhas de cada planta. Em microscópio estereoscópico contou-se o número de pústulas em cada folha e determinou-se o número de uredínias compreendidas em quatro discos de área igual a $1,13 \mathrm{~cm}^{2}$ (diâmetro $=1,2$ $\mathrm{cm}$ ), que foram retirados na região central de cada folha. Para determinação do número médio de esporos/uredínia, os quatro discos coletados por folha foram colocados em tubos de ensaio contendo $3 \mathrm{ml}$ de água + Tween $80(0,1 \%)$ e agitados em vortex por $5 \mathrm{~min}$, realizando-se duas leituras por tubo e determinando-se o número médio de urediniósporos em câmara de Neubauer. Como já se conhecia o número médio de uredínias em cada círculo, pode-se obter o número médio de esporos produzidos por uredínia.

\section{Efeito do tempo decorrido entre rizobacterização e ino-} culação do patógeno na indução de resistência sistêmica

Os isolados mais promissores avaliados no primeiro ensaio foram empregados no tratamento de mudas em dois diferentes tempos de pré-inoculação do patógeno. Um lote de plantas foi produzido em substrato tratado com rizobactérias, como descrito anteriormente, e outro lote recebeu a inoculação com os possíveis indutores de resistência apenas uma semana antes da inoculação com o patógeno. Para isso, usaram-se $30 \mathrm{ml}$ de cada suspensão bacteriana $\left(\right.$ Abs. $\left._{540 \mathrm{~nm}}=0,2\right)$ ou água estéril para irrigação do sistema radicular de cada muda. A inoculação com o patógeno e a condução do ensaio foram semelhantes às descritas no item anterior. Aos 13 dias da inoculação do patógeno, avaliou-se o número médio de pústulas por folha e o número médio de uredínias por área foliar. O ensaio foi montado em delineamento inteiramente casualizado, com cinco repetições, cada uma constituída de quatro plantas.

\section{RESULTADOS}

O uso da escala diagramática para ferrugem não permitiu separar o efeito das rizobactérias. Em todos os tratamentos, as folhas foram classificadas nas classes S2 e S3. Visando assegurar o melhor uso da escala, no segundo ensaio, determinou-se o diâmetro médio das pústulas e o número médio de uredínias/pústula, o que possibilitou a separação entre tratamentos, destacando-se os isolados FL2 e 3918 (Tabela 2).

No primeiro ensaio, para quatro isolados de rizobactérias (FL2, 3918, FL1 e MF4), o número médio estimado de pústulas por folha foi inferior à testemunha, destacando-se o isolado FL2. No segundo ensaio, tratamentos com todos os isolados bacterianos diminuíram o número de pústulas. Nesse ensaio, como no anterior, confirmou-se a maior eficiência de controle do isolado FL2, juntamente com o MF4, propiciando reduções superiores a $60 \%$ (Figura 1).

Nos dois ensaios, todos os isolados diferiram da testemunha não tratada quanto ao número médio de uredínias/área foliar. No ensaio 1, destacaram-se os isolados FL2, MF4, com reduções superiores a 77\% do número médio de uredínias por disco foliar $\left(1,13 \mathrm{~cm}^{2}\right)$ (Figura 2) e $39 \%$

TABELA 2 - Diâmetro médio de 40 pústulas, número médio de uredínias/pústula de Puccinia psidii e classes de severidade da ferrugem em mudas de eucalipto (Eucalyptus spp.) com 80 dias de idade tratadas com diferentes isolados de rizobactérias

\begin{tabular}{lccc}
\hline \hline Tratamento & $\begin{array}{c}\text { Diâmetro } \\
\text { médio de } \\
\text { pústula (mm) }\end{array}$ & $\begin{array}{c}\text { Número médio } \\
\text { de uredínias/ } \\
\text { pústula }\end{array}$ & $\begin{array}{c}\text { Classe de } \\
\text { severidade }\end{array}$ \\
\hline FL2 & 1,28 & $\mathbf{9 , 3 4}$ & $\mathrm{S} 2$ \\
3918 & 1,34 & 10,75 & $\mathrm{~S} 2$ \\
MF4 & 1,95 & 18,63 & $\mathrm{~S} 3$ \\
FL1 & 1,97 & 19,45 & $\mathrm{~S} 3$ \\
MF2 & 2,13 & 22,06 & $\mathrm{~S} 3$ \\
S2 & 2,45 & 20,34 & $\mathrm{~S} 3$ \\
S1 & 2,47 & 22,45 & $\mathrm{~S} 3$ \\
R1 & 2,52 & 35,25 & $\mathrm{~S} 3$ \\
CIIb & 2,61 & 34,54 & $\mathrm{~S} 3$ \\
Ca & 2,66 & 30,32 & $\mathrm{~S} 3$ \\
Testemunha & 2,66 & 31,54 & $\mathrm{~S} 3$ \\
\hline
\end{tabular}



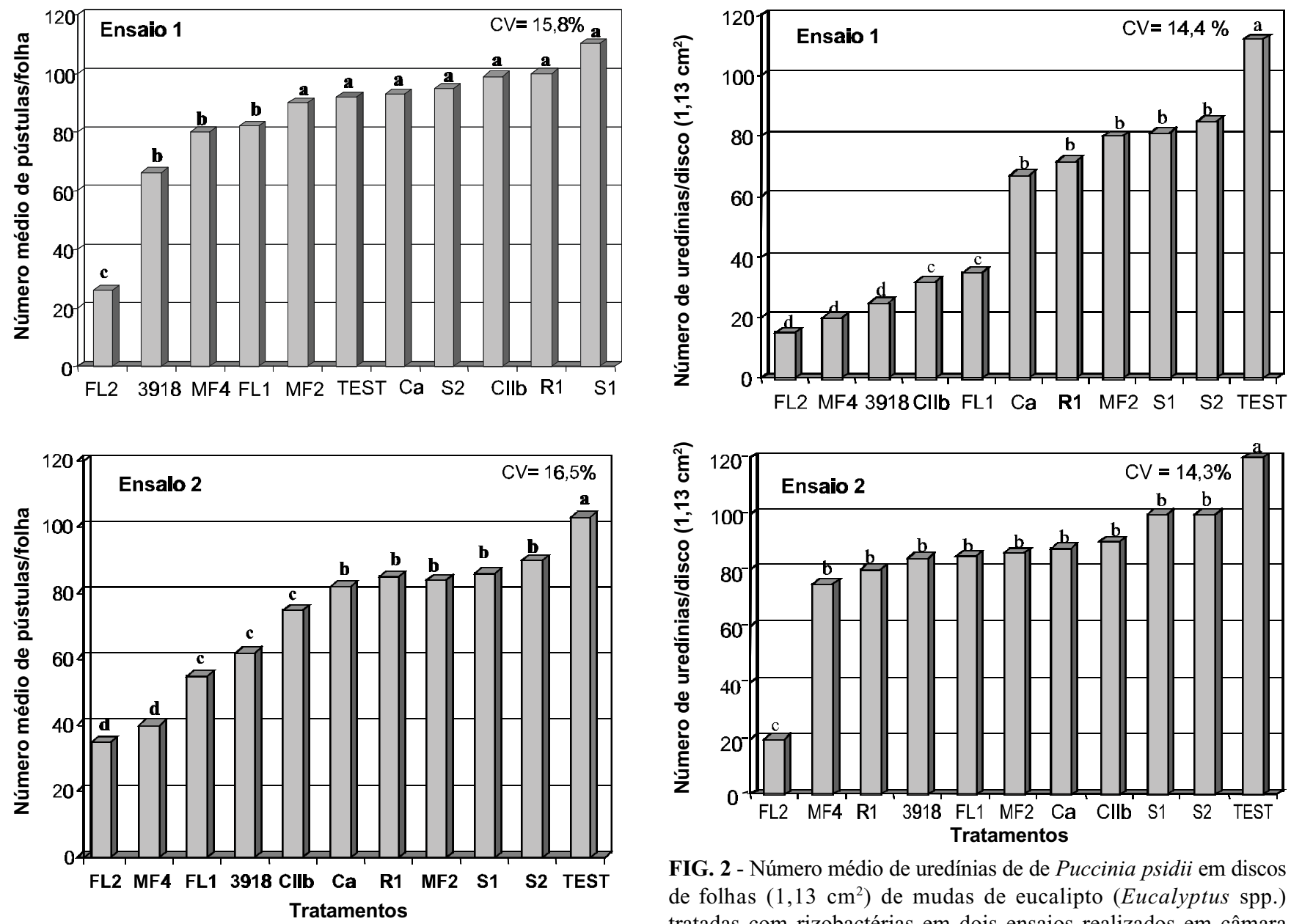

FIG. 2 - Número médio de uredínias de de Puccinia psidii em discos de folhas $\left(1,13 \mathrm{~cm}^{2}\right)$ de mudas de eucalipto (Eucalyptus spp.) tratadas com rizobactérias em dois ensaios realizados em câmara de crescimento. Médias com mesma letra não diferem estatisticamente entre si pelo teste de Scott-Knott, ao nível de 5\% de probabilidade. em dois ensaios realizados em câmara de crescimento. Médias com mesma letra não diferem estatisticamente entre si pelo teste de Scott-Knott, ao nível de 5\% de probabilidade.

no número médio de esporos/uredínia (Figura 3). Além deles, os isolados 3918 e Ca também se destacaram na redução do número médio de uredínias/área foliar e de esporos/uredínias, respectivamente. No ensaio 2, destacou-se o isolado FL2 na redução do número médio de uredínias/área foliar. Para número de esporos/uredínia, somente o isolado S2 não diferiu da testemunha (Figura 3). Dois dos melhores isolados (FL2 e MF4) do ensaio 1 se mantiveram como melhores no segundo ensaio.

Os dois melhores isolados testados diferiram da testemunha quanto às variáveis avaliadas nos dois tempos de tratamento testados. Todavia, a redução na severidade foi mais acentuada quando as mudas foram enraizadas em substrato tratado com rizobactérias, 80 dias antes da inoculação do patógeno (Figura 4).

\section{DISCUSSÃO}

A indução de resistência envolve a participação de um

agente indutor, o qual pode ser um ativador químico como os derivados benzotiadiazólicos e outros compostos (Friedrich et al., 1996; Benhamou \& Belanger, 1998), extratos de células de microrganismos (Romeiro \& Kimura, 1997) ou microrganismos vivos (Liu et al., 1995a; Liu et al., 1995b; Liu et al., 1995c; Hoffland et al., 1996). As rizobactérias promotoras do crescimento de plantas incluem-se neste último caso (Kloepper, 1996). Alguns isolados de rizobactérias, promotoras de crescimento em eucalipto, podem provavelmente induzir resistência sistêmica à ferrugem em Eucalyptus spp. Dos dez isolados testados, FL2 [Pseudomonas aeruginosa (Schroeter) Migula] e MF4 (Pseudomonas sp.) se destacaram em reduzir a severidade da doença. Isolados de Pseudomonas spp., especialmente do grupo fluorescente, são freqüentemente relatados como indutores de ISR em culturas agronômicas (Maurhofer et al., 1994, Van Loon et al., 1997). Nesse sentido, já foi comprovado que um isolado de $P$. aeruginosa (KMPCH) induziu resistência a Botrytis cinerea Pers. Ex Fries em tomate (Lycopersicon esculentum Mill.). A colonização de raízes pelo isolado resultou em aumento no nível de ácido salicílico,

Fitopatol. bras. 30(4), jul - ago 2005 

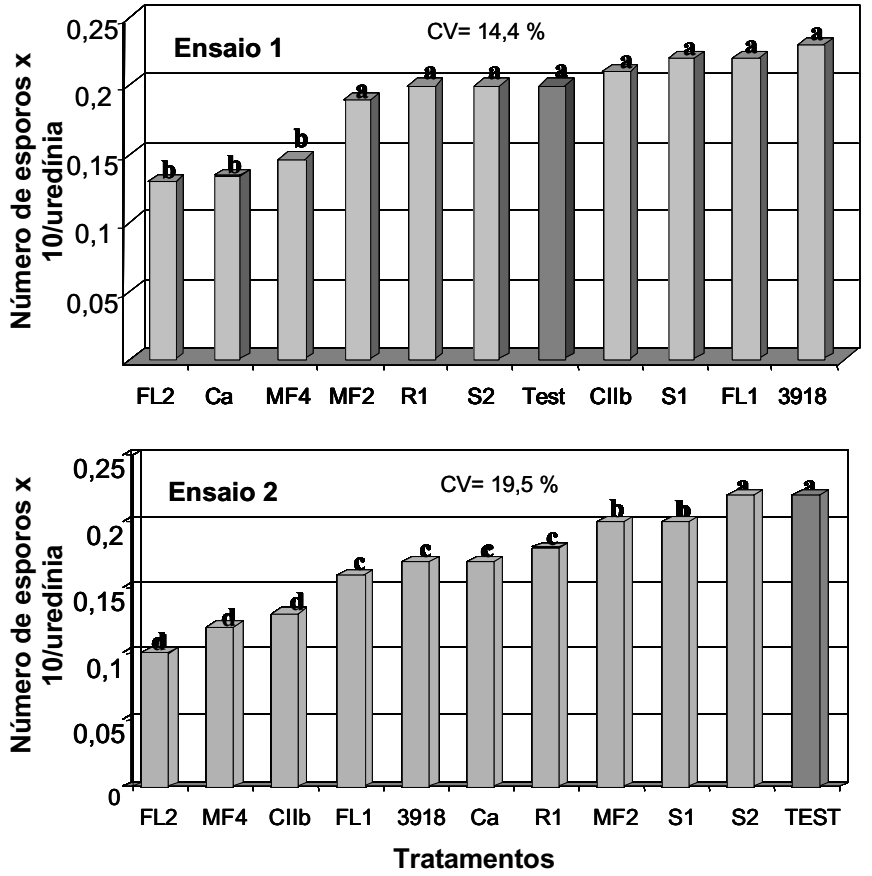

FIG. 3 - Número médio de esporos de Puccinia psidii por uredínias presentes em folhas de mudas de eucalipto (Eucalyptus spp.) tratadas com rizobactérias em dois ensaios realizados em câmara de crescimento. Médias com mesma letra não diferem estatisticamente entre si pelo teste de Scott-Knott, ao nível de 5\% de probabilidade.

aparentemente produzido pela rizobactéria, e na atividade da enzima fenilalanina amônia liase (Audenaert et al., 2002a). Similarmente, foi observado um incremento no nível de ácido salicílico em raízes de feijoeiro (Phaseolus vulgaris L.) colonizadas pelo mesmo isolado (11,5 ng/g de raízes) (De Meyer et al., 1999b) e em fumo (Nicotiana tabacum L.) pelo isolado $\mathrm{CHAO}(45,3 \mathrm{ng} /$ planta $)$ pertencente à mesma espécie com indução de resistência e aumento no nível de ácido salicílico (Maurhofer et al., 1998). Outro isolado (7NSK2) de $P$. aeruginosa produtor de três tipos de sideróforos, sob condições de limitação de ferro, foi capaz de induzir resistência à $B$. cinerea em feijão e tomate (De Meyer \& Höfte, 1997; De Meyer et al., 1999b; Audenaert et al., 2002b), a Colletotrichum lindemuthianum (Sacc. \& Magn.) em feijão (Bigirimana \& Höfte, 2002) e ao Tobacco mosaic virus (TMV) em fumo (De Meyer et al., 1999a). Em todos estes sistemas, a comprovação da indução de resistência foi demonstrada usando mutantes para produção de sideróforos (Audenaert et al., 2002a).

Na área florestal, Eneback \& Carey (2000) sugeriram que isolados de Bacillus sp. induzem resistência sistêmica à ferrugem em Pinus spp.. Os principais efeitos observados no estudo com rizobactérias incluem o maior crescimento de raízes, da parte aérea e aumento no rendimento da planta. Acredita-se que, indiretamente, o controle biológico, seja por antibiose direta ou por indução de resistência, esteja relacionado a estes incrementos na produção. Neste último
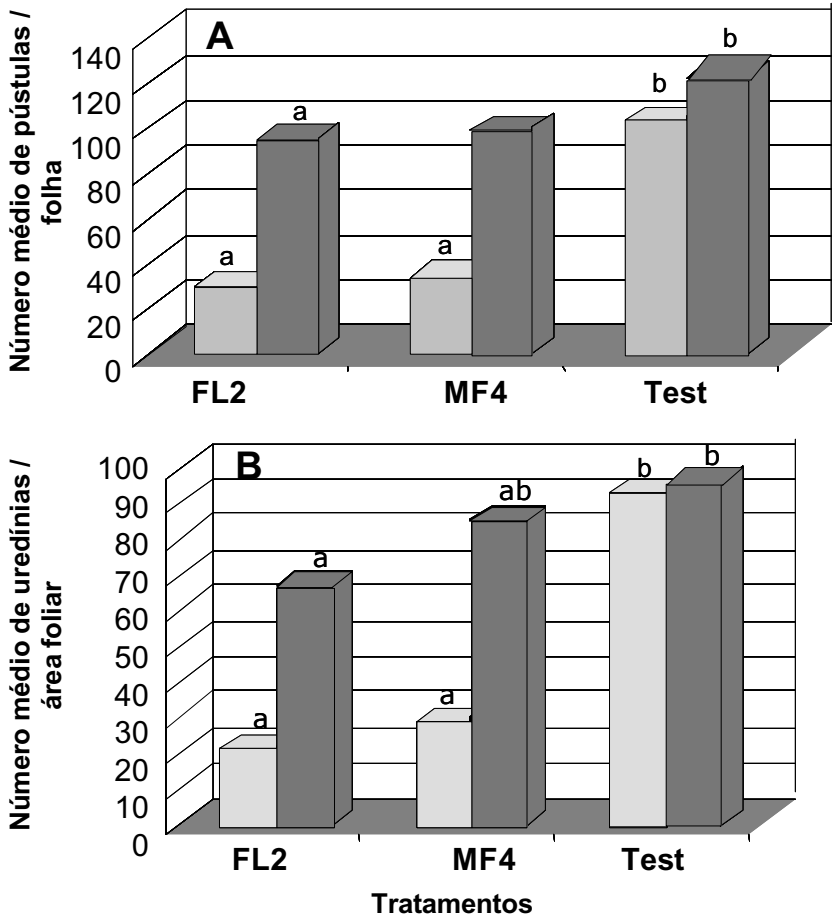

$\square$ Tempo de exposição $=80$ dias

- Tempo de exposição $=7$ dias

FIG. 4 - Número médio de pústulas (A) e de uredínias (B) de Puccinia psidii por área foliar $\left(1,13 \mathrm{~cm}^{2}\right)$ presentes em folhas de mudas de eucalipto (Eucalyptus spp.) tratadas com rizobactérias em dois períodos (sete ou 80 dias) antes da exposição ao patógeno. No mesmo tempo de exposição, médias com mesma letra não diferem estatisticamente entre si pelo teste de Tukey, ao nível de $5 \%$ de probabilidade.

caso, a comprovação científica da existência de indução de resistência e da não ocorrência dos mecanismos de antibiose direta pode ser conseguida pela compartimentalização, a nível espacial, dos componentes microbianos da interação, ou seja, a presença e, ou, adição de rizobactérias à rizosfera torna a parte aérea mais resistente a patógenos, embora estejam espacialmente separados (Liu et al., 1995c; Kloepper, 1996; Raupach et al., 1996; Wei et al., 1996).

A separação espacial entre o agente indutor de resistência e o patógeno é um indicativo do envolvimento de mecanismos de resistência induzida. No entanto, não se pode descartar a possibilidade de que algum sinal bioquímico produzido pelo agente indutor seja absorvido pela planta e atue na parte aérea (Romeiro, 1999). Nesse sentido, existem alguns critérios básicos para investigar a existência de resistência sistêmica induzida, entre eles deve ocorrer um intervalo de tempo entre a exposição da planta ao indutor e a expressão da resistência. Para os dois isolados testados, observou-se uma redução na severidade de ferrugem mesmo no menor tempo testado (uma semana). No entanto, essa redução foi bem mais acentuada quando as mudas foram produzidas em substrato rizobacterizado (mudas com 80 
dias). Segundo Van Loon et al. (1998) é necessário haver um intervalo mínimo entre o tratamento com rizobactéria e a inoculação do patógeno para que a planta entre em estado de indução e a resistência sistêmica se expresse. Em geral, com plantas anuais, esse tempo é de aproximadamente uma semana. No entanto, Eneback \& Carey (2000) observaram resistência sistêmica induzida à ferrugem por isolados de PGPRs em Pinus spp., decorridas quatro semanas entre tratamento com o indutor e inoculação com basidiósporos do patógeno. Provavelmente, para plantas perenes como eucalipto e pinus, é necessário um tempo maior que o observado nas plantas anuais para que a resistência seja plenamente manifestada, como ficou evidenciado pelo presente trabalho.

Segundo Steiner \& Schönbeck (1995), alguns critérios devem ser observados para se determinar o envolvimento de resistência sistêmica: a- ausência de efeitos tóxicos diretos do organismo de biocontrole sobre o patógeno; b- a ISR pode ser inibida por uma aplicação prévia de inibidores específicos da expressão gênica na planta; c- necessidade de um intervalo de tempo para a plantar expressar essa resistência; $d$ - ausência da relação entre resistência e quantidade crescente de indutor; e- amplo espectro de atuação contra vários patógenos (inespecificidade da proteção); f- ocorrer local e sistemicamente; g- dependente do genótipo da planta e seu nível de resistência. Diante destes aspectos, o presente trabalho apenas evidenciou uma possível indução de resistência sistêmica mediada por rizobactérias em eucalipto, devendo-se então realizar outras investigações para comprovar esta hipótese.

Vários tipos de respostas ativas poderiam ser induzidas nas plantas para impedir o desenvolvimento do patógeno, dentre estas podem ser citadas o acúmulo de PRPs nos espaços intercelulares e nos vacúolos, lignificação e formação de papilas (Van Loon et al., 1998). Os mecanismos de defesa envolvidos na indução mais conhecidos são o acúmulo de proteínas relacionadas com a patogênese e a lignificação. No primeiro caso, a ação ocorre diretamente quando o acúmulo ocorre nos espaços intercelulares ou indiretamente quando ocorre nos vacúolos. Além disso, as proteínas relacionadas com a patogênese apresentam alta atividade antimicrobiana in vitro e podem também promover a liberação de eliciadores de fitoalexinas ou induzirem a síntese de compostos fenólicos. Embora o mecanismo de lignificação ainda seja pouco estudado, sabe-se que a síntese de lignina é uma resposta de resistência, potencialmente induzida por agentes bióticos e abióticos, de caráter sistêmico e que pode estar intrinsecamente associada a SAR/ISR (Romeiro, 1999). Estudos histológicos, bioquímicos e fisiológicos buscando detectar algumas dessas modificações nas plantas tratadas com os isolados de rizobactérias podem fornecer um maior embasamento para se explicar melhor a expressão da resistência.

Trabalhos futuros buscando-se determinar o tempo que essa resistência permanece efetiva, bem como a sua atuação sobre outros patógenos foliares, devem ser conduzidos e poderão explicar melhor o papel desses isolados na indução de resistência. A obtenção de minicepas com resistência sistêmica à ferrugem pode ser muito importante no manejo dessa doença nos viveiros florestais, propiciando a diminuição ou até redução do uso de fungicidas, bem como o aumento da disponibilidade de brotos aptos a serem utilizados na propagação clonal. Outro fator a considerar é a possibilidade de que os brotos coletados nessas mudas possam apresentar uma maior proteção também contra patógenos causadores de podridão de estacas, quando expostos às condições de enraizamento. Além disso, não se pode descartar a possibilidade dos isolados bacterianos atuarem como antagonistas por meio de outros mecanismos de biocontrole, como antibiose ou produção de sideróforos, o que poderia ser potencializado com uma ou mais aplicação dos isolados no substrato de enraizamento.

\section{AGRADECIMENTOS}

Os autores gostariam de expressar os seus agradecimentos às empresas florestais Aracruz Celulose S.A., CAF Santa Bárbara Ltda., Cenibra S.A., International Paper do Brasil, Jari Celulose S.A., Klabin S.A., Lwarcel Celulose e Papel Ltda., Plantar S.A., Suzano Bahia Sul Celulose S.A. e Veracel Celulose S.A., pelo apoio logístico e financiamento.

\section{REFERÊNCIAS BIBLIOGRÁFICAS}

ALFENAS, A.C. \& MAFIA, R.G. Controle integrado de doenças em viveiros clonais e aspectos relativos à ferrugem (Puccinia psidii) do eucalipto. Fitopatologia Brasileira 28:156-163. 2003.

AUDENAERT, K., PATTERY, T., CORNELIS, P. \& HÖFTE, M. Induction of systemic resistance to Botrytis cinerea in tomato by Pseudomonas aeruginosa 7NSK2: role of salicylic acid, pyochelin, and pyocyanin. Molecular Plant-Microbe Interactions 15:1147-1156. 2002a.

AUDENAERT, K., DE MEYER, G. \& HÖFTE, M. Abscisic acid determines basal susceptibility of tomato to Botrytis cinerea and suppresses salicylic acid-dependent signaling mechanisms. Plant Physiology 128:491-501. 2002b.

BENHAMOU, N. \& BELANGER, R.R. Induction of systemic resistance to Pythium damping-off in cucumber plants by benzothiadiazole: ultrastructure and cytochemistry of the host response. Plant Journal 14:13-21. 1998.

BIGIRIMANA, J. \& HÖFTE, M. Induction of systemic resistance to Colletotrichum lindemuthianum in bean by a benzothiadiazole derivative and rhizobacteria. Phytoparasitica 30:159-168. 2002.

CAMPINHOS JR., E. Sustainable plantations of high-yield Eucalyptus trees for production of fiber: the Aracruz case. New Forests 17:129143. 1999.

DE MEYER, G., AUDENAERT, K. \& HÖFTE, M. Pseudomonas aeruginosa 7NSK2-induced systemic resistance in tobacco depends on in planta salicylic acid but is not associated with PR1a geneexpression. European Journal of Plant Pathology 105:513-517. 1999a.

DE MEYER, G., CAPIAU, K., AUDENAERT, K., BUCHALA, A., MÉTRAUX, J.P. \& HÖFTE, M. Nanogram amounts of salicylic acid produced by the rhizobacterium Pseudomonas aeruginosa 7NSK2 
activate the systemic acquired resistance pathway on bean. Molecular Plant-Microbe Interactions 12:450-459. 1999b.

DE MEYER, G. \& HÖFTE, M. Salicylic acid produced by the rhizobacterium Pseudomonas aeruginosa 7NSK2 induces resistanceto leaf infection by Botrytis cinerea in bean. Phytopathology 87:588-593. 1997.

ENEBACK, S.A. \& CAREY, W.A. Evidence for induced systemic protection to fusiform rust in loblolly pine by plant growth promoting rhizobacteria. Plant Disease 84:306-308. 2000.

FAO. Global forest resources assessment 2000 - Main report. FAO Forestry paper. ISSN 0258-6150, 479p. 2000. (www.fao.org/ forestry/fo/fra/main/index.jsp).

FRIEDRICH, L., LAWTON, K., RUESS, W., MASNER, P., SPECHER, N., RELLA, M.G., MEIER, B., DINCHER, S., STAUB, T. \& UKNES, S. A benzothiadiazole derivative induces systemic acquired resistance in tobacco. Plant Journal 10:61-70. 1996.

HOFFLAND, E., HAKULINEN, J. \& VAN PELT, J.A. Comparison of systemic resistance induced by a avirulent and nonpathogenic Pseudomonas species. Phytopathology 86:757-762. 1996.

JUNGHANS, D.T. Quantificação da severidade, herança da resistência e identificação de marcadores RAPD ligados à resistência à ferrugem (Puccinia psidii) em Eucalyptus grandis. (Tese de Doutorado). Viçosa. Universidade Federal de Viçosa. 2000.

KADO, C.I. \& HESKETT, M.S. Selective media for isolation of Agrobaterium, Corynebacterium, Erwinia, Pseudomonas and Xanthomonas. Phytopathology 60:969-976, 1970.

KLOEPPER, J.W. Host specificity in microbe-microbe interctions. Bio Science 46:406-409. 1996.

KLOEPPER, J.W., TUZUN, S. \& KUC, J.A. Proposed definitions related to induced disease resistance. Biocontrol Science Technology 2:349-351. 1992.

LIU, L., KLOEPPER, J.W. \& TUZUN, S. Induction of systemic resistance in cucumber against bacterial angular leaf spot by plant growth-promoting rhizobacteria. Phytopathology 85:843-847. 1995a.

LIU, L., KLOEPPER, J.W. \& TUZUN, S. Induction of systemic resistance in cucumber against Fusarium wilt by plant growthpromoting rhizobacteria. Phytopathology 85:695-698. 1995b.

LIU, L., KLOEPPER, J.W. \& TUZUN, S. Induction of systemic resistance in cucumber by plant growth-promoting rhizobacteria: duration of protection and effect of host resistance on protection and root colonization. Phytopathology 85:1064-1068. 1995c.

MAURHOFER, M., HASE, C., MEUWLY, P., MÉTRAUX, J.P. \& DÉFAGO, G. Induction of systemic resistance of tobacco to tobacco necrosis virus by the root colonizing $P$. fluorescens strain CHAO: Influence of gacA and of pyoverdine production. Phytopathology
$84: 139-146,1994$

MAURHOFER, M., REIMMANN, C., SCHMIDLI-SACHERER, P., HEEB, S., HAAS, D. \& DÉFAGO, G. Salicylic acid biosynthetic genes expressed in Pseudomonas fluorescens strain P3 improve the induction of systemic resistance in tobacco against tobacco necrosis virus. Phytopathology 88:678-684. 1998.

MORA, A.L. \& GARCIA, C.H. A cultura do eucalipto no Brasil. Sociedade Brasileira de Silvicultura, São Paulo, SP. 2000.

PIETERSE, C.M.J., VAN WEES, S.C.M., VAN PELT, J.A., KNOESTER, M., LAAN, R., SHAH, J., TSUI, F. \& KLESSIG, D.F. Characterization of a salicylic acid-insensitive mutant (sai 1) of Arabidopsis thaliana, identified in a selective screen utilizing the SA - induce expression of the tms 2 gene. Molecular PlantMicrobe Interactions 10:69-78. 1997.

RAUPACH, G.S., LIU, L., MURPHY, J.F., TUZUN, S. \& KLOEPPER, J.W. Induced systemic resistance in cucumber and tomato against cucumber mosaic cucumovirus using plant growthpromoting rhizobacteria (PGPR). Plant Disease 80:891-894. 1996. ROMEIRO, R.S. Indução de Resistência em plantas a patógenos. Viçosa, UFV. Cadernos didáticos, 56. 1999.

ROMEIRO, R.S. \& KIMURA, O. Induced resistance in pepper leaves infiltrated with purified elicitors from Xanthomonas campestris pv. vesicatoria. Journal of Phytopathology 145:495-498. 1997.

RUIZ, R.A.R., ALFENAS, A.C., FERREIRA, F.A. \& VALE, F.X.R Influência da temperatura, do tempo de molhamento foliar, do fotoperíodo e da intensidade de luz sobre a infecção de Puccinia psidii em eucalipto. Fitopatologia Brasileira 14:55-61. 1989.

STEINER, U. \& SCHÖNBECK, F. Induced disease in monocots. In: Hammerschmidt, R. \& Kuc, J. (Eds.). Induced resistance to disease in plants (Development in Plant Pathology, vol. 4). Kluwer Academic Pub., Dordrech. 1995. pp.86-110.

TEIXEIRA, D.A. Promoção de enraizamento e indução de resistência sistêmica à ferrugem e à mancha-de-Cylindrocladium, mediadas por rizobactérias em clones de Eucalyptus spp. (Tese de Doutorado). Viçosa. Universidade Federal de Viçosa. 2001.

VAN LOON, L.C., BAKKER, P.A.H.M. \& PIETERSE, C.M.J. Systemic resistance induced by rhizosphere bacteria. Annual Review of Phytopathology 36:453-483. 1998.

VAN LOON, L.C., BAKKER, P.A.H.M. \& PIETERSE, C.M.J. Mechanisms of PGPR-induced resistance against pathogens. In: Proc. of Fourth Int. workshop on plant-growth-promoting rhizobacteria. Sapporo, Japan, 1997. pp.50-57.

WEI, G., KLOEPPER, J.W. \& TUZUN, S. Induced systemic resistance to cucumber diseases and increased plant growth by plant growth-promoting rhizobacteria under field conditions. Phytopathology 86:221-224. 1996. 